\title{
FATIGUE STRENGTH CHARACTERISTICS OF WELDED STUD JOINT WITH RESPECT TO STEEL PLATE THICKNESS
}

\author{
John S.E. Koh ${ }^{1, *}$, O. Minata ${ }^{2}$ and A. Muranaka ${ }^{3}$ \\ ${ }^{1}$ Consulting Engineer, Structural Technology Division, Fukken Co., Ltd. Consulting Engineers, \\ 10-11, 2-Chome Hikari-Machi, Higashi-Ku, Hiroshima 732-0052, Japan \\ ${ }^{2}$ Professor, Graduate School of Engineering, Hiroshima Institute of Technology, Japan \\ ${ }^{3}$ Assistant Professor, Graduate School of Engineering, Hiroshima Institute of Technology, Japan \\ *(Corresponding author: E-mail: john@fukken.co.jp or johnhitjp@yahoo.co.jp)
}

\begin{abstract}
Since 1954, a great number of study and research has been carried out on fatigue behaviors of stud shear connectors and much useful information have been obtained and reported. Nowadays, stud is becoming the most common type of mechanical shear connector available and it is being used exclusively in composite structure such as bridge, large gravity type structure (breakwater, bulkhead wharf, coastal revetment etc) and Very Large Floating Structure (VLFS) consists of hybrid caisson and pontoon. Hybrid caisson and pontoon structure used at the coast and offshore is built from multiple layers of extremely thin steel plate which form the box of steel shell where large number of studs are welded onto it and embedded into concrete. Over decades, stud has been of important role as shear connector in composite structure; a number of rules and regulations have been set for its design and application. However, at present, the fatigue strength relation between stud diameter (d) and steel plate thickness (t) is not being established in any design guidelines or specifications for steel structure. In such present condition, this research is carried out to establish a fatigue design method with respect to diameter-thickness relation of stud and steel plate by conducting experiment on a series of test specimens. A modified S-N fatigue equation by introducing $\mathrm{d} / \mathrm{t}$ element based on the results from experimental data is introduced here as a future reference for design of stud and steel structure.
\end{abstract}

Keywords: Stud; mechanical shear connector; thin steel plate; stud diameter; steel plate thickness; modified S-N fatigue equation

\section{INTRODUCTION}

Hybrid caisson and pontoon structures are often used as pier (quay, wharf, dock etc.) and floating wave-absorbing structures [1]. Normally, the inner sections are made from shell of steel plates embedded in concrete and these two elements are tied together by using a large number of studs.

At present, the strength characteristic between the stud diameter and steel plate thickness is not being considered for the design of hybrid caisson and pontoon structure. This research is carried out with the aim to establish fatigue design method for offshore hybrid structure by conducting experiment on series of test specimens under two objectives :

i ) Study the fatigue strength of thin steel plate welded with studs

ii) Study the fatigue strength of thin steel plate welded with group of studs

\section{OUTLINE OF TEST SPECIMEN}

The studs are of 'round headed' type. It is made from material called Si-Killed Steel based on Design Specification for Highway Bridge of Japan Road Association. Headed studs are used exclusively as shear connectors in various steel-concrete composite constructions [2]. Round headed stud (Figure 1) consists of a bolt that is electrically welded to the steel member using an automatic welding procedure. Stud welding process is conducted using electric arc method. 
Steel plates are of type SS400 according to Japan Industrial Standard:JIS, and the mechanical properties are as shown in Table 1. According to past research, there are three types of typical crack failures that can occur as shown in Figure 2 [3].

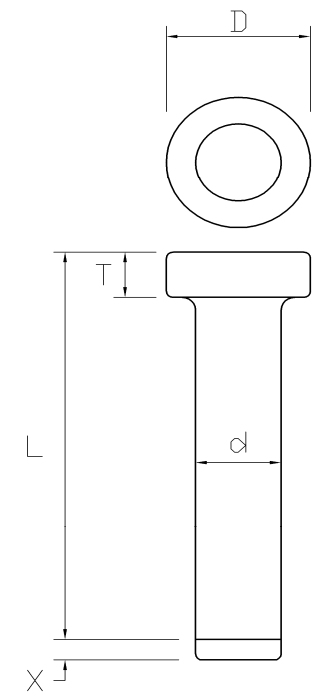

Figure 1. Dimensions of Round Headed Stud

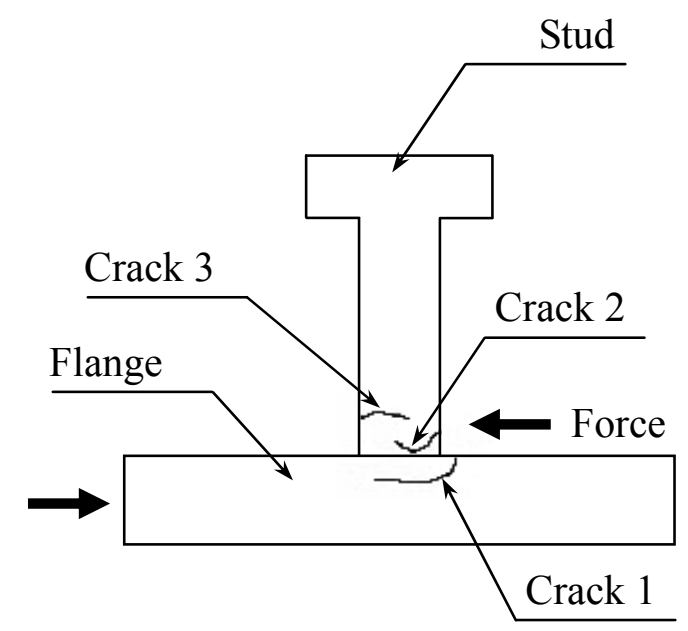

Figure 2. Typical Types of Crack Failure

Table 1. Mechanical Property of JIS:SS400

\begin{tabular}{|c|c|c|c|}
\hline Type & $\begin{array}{c}\text { Yield stress } \\
\left(\mathrm{N} / \mathrm{mm}^{2}\right)\end{array}$ & $\begin{array}{c}\text { Tensile strength } \\
\left(\mathrm{N} / \mathrm{mm}^{2}\right)\end{array}$ & $\begin{array}{c}\text { Elongation } \\
(\%)\end{array}$ \\
\hline $\begin{array}{c}\text { SS400 } \\
\text { (below } 16 \mathrm{~mm})\end{array}$ & Above 245 & $400-510$ & Above 20 \\
\hline
\end{tabular}

\subsection{Steel Plate Welded With Studs}

Specimen consists of $700 \times 80 \mathrm{~mm}$ steel plate welded with two different stud diameters (Figure 3). Combination for stud diameter, $\mathrm{d}$ of $13,16,19,22 \mathrm{~mm}$ and plate thickness, $\mathrm{t}$ of $6,12,22 \mathrm{~mm}$ are used.

\subsection{Steel Plate Welded With Group of Studs}

Two different types of specimen (type A and type B) are used; each consists of $620 \times 210 \times 9 \mathrm{~mm}$ steel plate welded with six studs of $13 \mathrm{~mm}$ diameter (Figure 4).

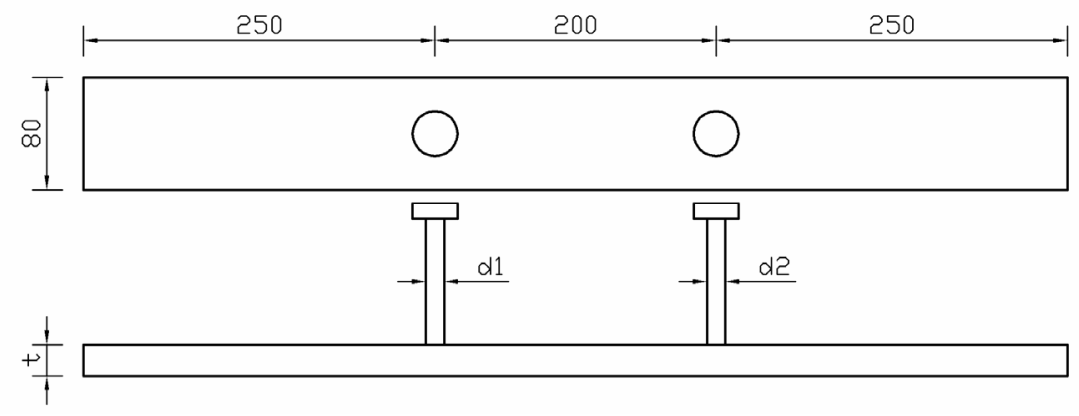

Figure 3. Dimensions of Plate Welded with Studs 

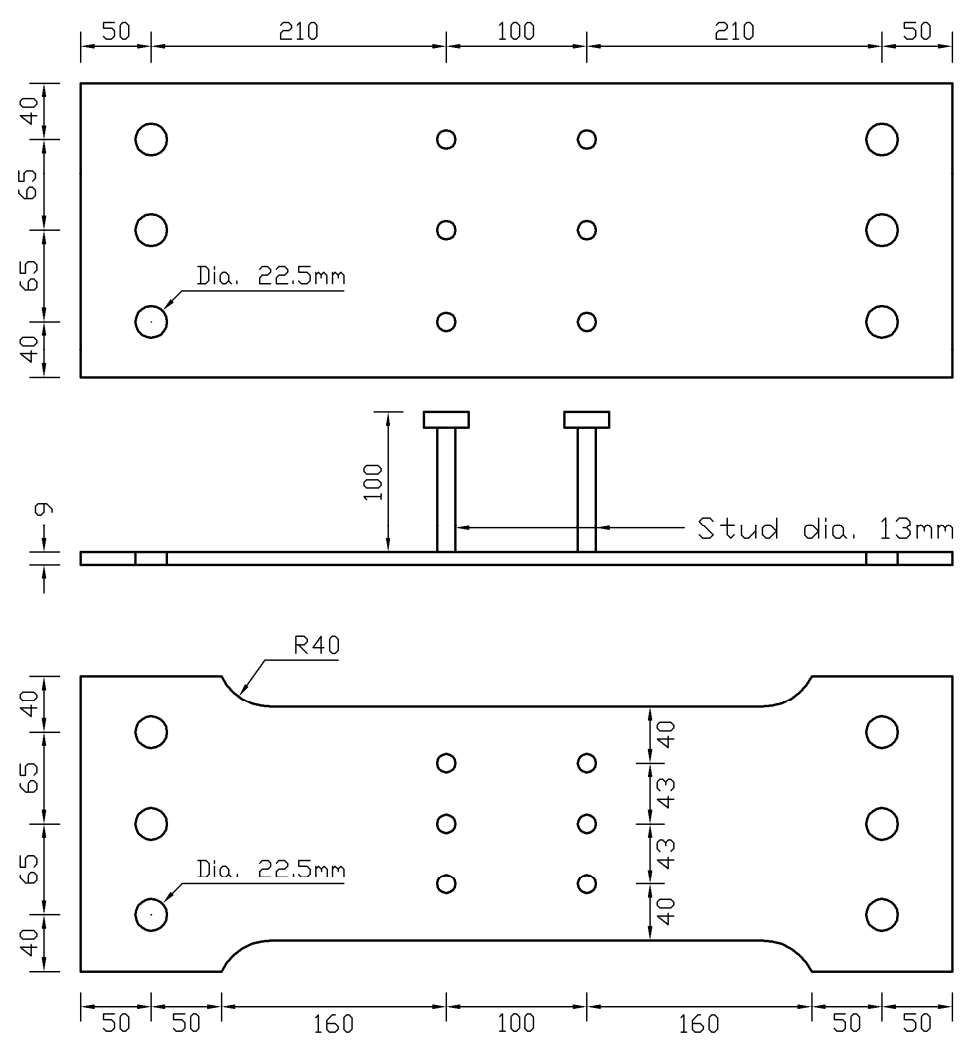

Plan view : type A (above); type B (below)

Figure 4. Dimensions of Plate Welded with a Group Studs

\section{TEST PROCEDURES}

Fatigue tests are conducted using Shimadzu test machine model EHF-U50. Uni-directional form of loading (Figure 5) is applied to test specimens. Minimum load is set to zero and axial tensile cyclic load is applied at 480 cycles per $\min (8 \mathrm{hz})$ to one end of steel plate with the other end in fixed state. For specimens with group studs, steel plate is clipped at both ends with two slices of steel plates using 3 bolts ( $\phi 22.5 \mathrm{~mm}$ ) at each end (Figure 4) before load is applied. During testing, maximum and minimum loads are automatically kept constant at the preselected values. Testing for plate welded with studs is conducted until complete failure; testing for group studs is terminated at 'passing-through crack' state.

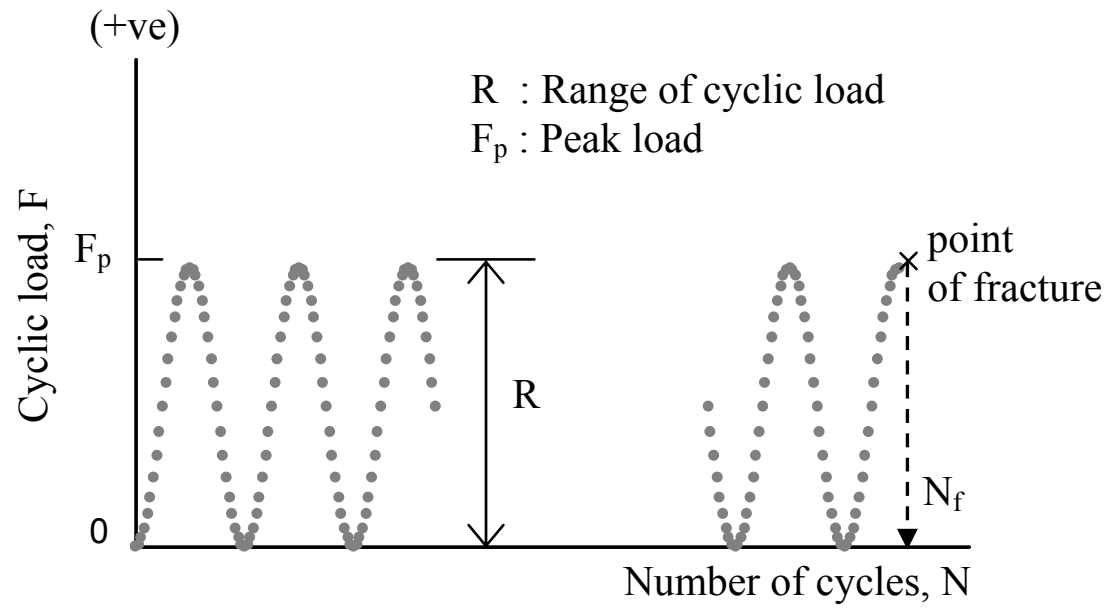

Figure 5. Uni-directional Form of Fatigue Test Loading 


\section{TEST RESULTS AND EVALUATIONS}

14 specimens from various combinations of stud diameter and steel plate thickness are tested for steel plate welded with studs ( 2 studs/specimen) while 6 specimens ( 6 studs $=1$ group/specimen $)$ are tested for steel plate welded with group of studs. All specimens failed by crack line perpendicular to longitudinal axis at weld toe. Test results for one stud $(14 \times 2=28$ data $)$ and group of studs $\left(6 \times 1=6\right.$ data) are plotted in Figure 6 . In Figure 6 , it can be seen that at $\mathrm{N}_{\mathrm{f}}=2 \times 10^{6}$ cycles, S-N curve for 'group of studs' (at passing-through crack state) is lower compare to 'one stud'. This shows that fatigue strength decreases with increasing number of stud welded on the steel plate. Next, fatigue strength for different $\mathrm{d} / \mathrm{t}$ ratio $(\mathrm{d}=$ stud diameter; $\mathrm{t}=$ plate thickness $)$ are extracted from one stud data as shown in Figure 7. It can be seen that the fatigue strength decrease with increasing in $\mathrm{d} / \mathrm{t}$. Note that all test results meet the minimum requirement for Fatigue Design Code for Steel Structures by Japanese Society of Steel Construction (JSSC) Class E design curve [4].

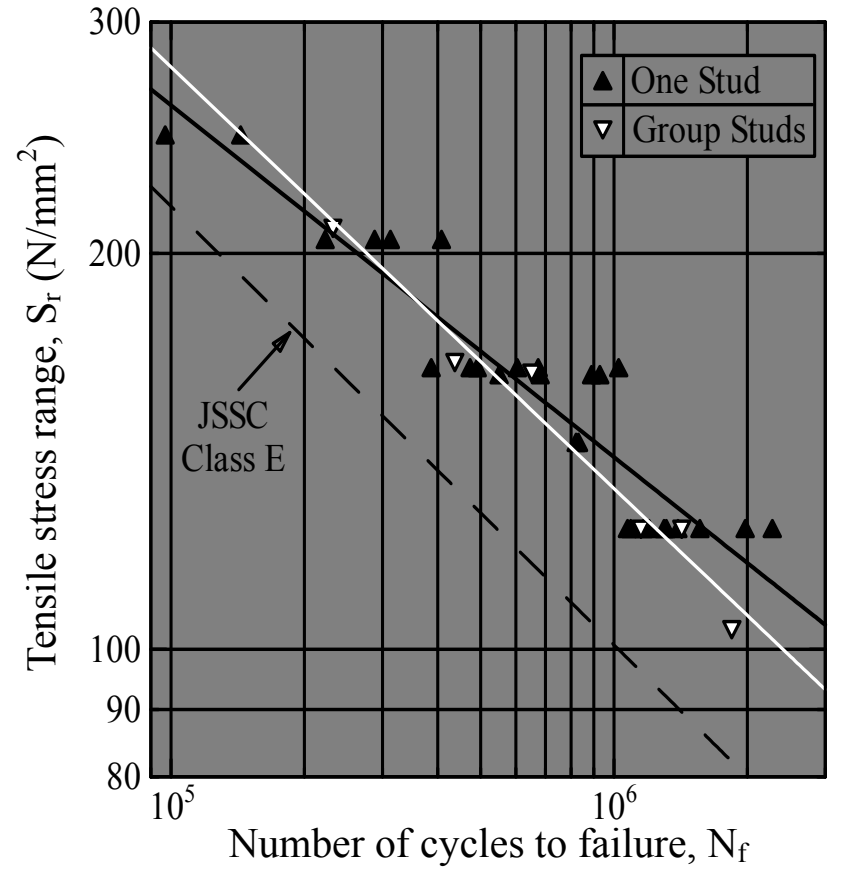

Figure 6. S-N Curve for Test Results of One Stud and Group of Studs Data

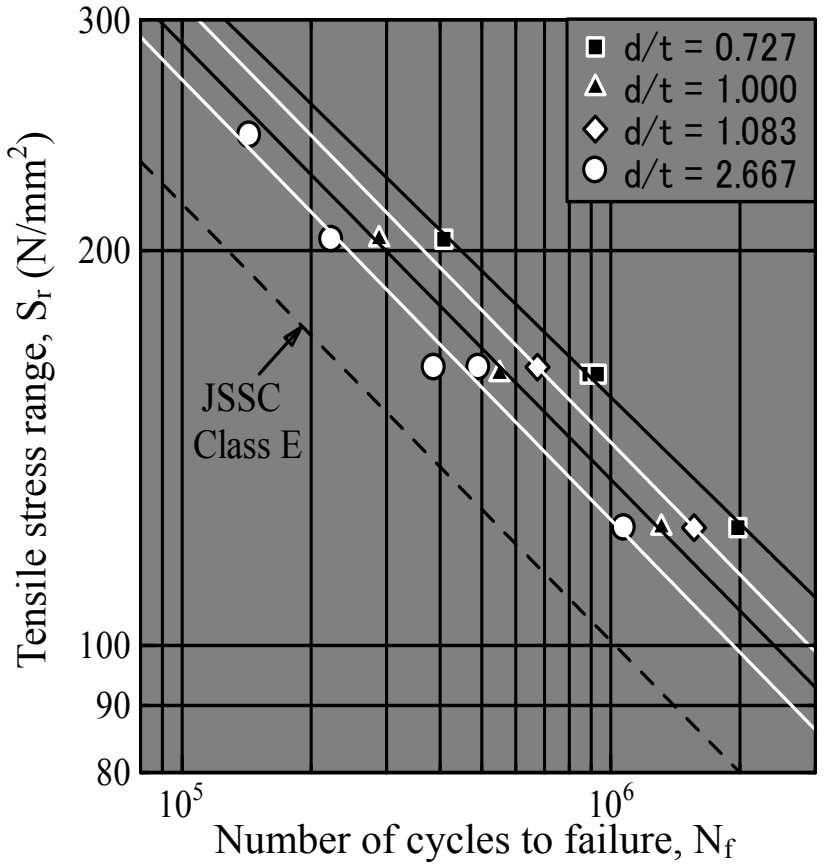

Figure 7. S-N Curve for d/t Ratio Extracted from One Stud Data in Figure 6

From Figure 6, mean value for fatigue strength of 'one stud', $\mu=116.35 \mathrm{~N} / \mathrm{mm}^{2}$ is obtained at $\mathrm{N}_{\mathrm{f}}=$ $2 \times 10^{6}$ cycles and standard deviation is calculated as $\sigma=11.91 \mathrm{~N} / \mathrm{mm}^{2}$. Using statistic equation [5] as shown by Eq. (1), value of $\mu$ and $\sigma$ at probability of failure, $2.5 \%$ of normal distribution as suggested by JSSC are obtained for number of studs, $n=1,5,10,15,20$ and 25 . Normal distribution graph are plotted in Figure 8 for respective $n$.

$$
\begin{aligned}
& p_{\text {min }}(x)=n\left[1-\Phi\left(\frac{x-\mu}{\sigma}\right)\right]^{n-1} \phi\left(\frac{x-\mu}{\sigma}\right) \frac{1}{\sigma} \\
& P_{\text {min }}(x)=1-\left[1-\Phi\left(\frac{x-\mu}{\sigma}\right)\right]^{n}
\end{aligned}
$$

From Figure 8, it can be seen that fatigue strength decrease exponentially; $\mu$ and $\sigma$ decrease with increasing number of studs. Using $\mu=116.35 \mathrm{~N} / \mathrm{mm}^{2}$ and $\sigma=11.91 \mathrm{~N} / \mathrm{mm}^{2}$, number of studs that are needed to meet the minimum requirement for JSSC Class E curve (given by $\mathrm{S}_{\mathrm{r}}=80 \mathrm{~N} / \mathrm{mm}^{2}$ at 
$\mathrm{N}_{\mathrm{f}}=2 \times 10^{6}$ cycles) is calculated and the result gives $n=23$. This means that maximum number of studs that can be welded in a row for an area of steel plate surface in the direction of force is 23 studs $(n \leq 23)$. The result is illustrated in Figure 9 for $n=23$.

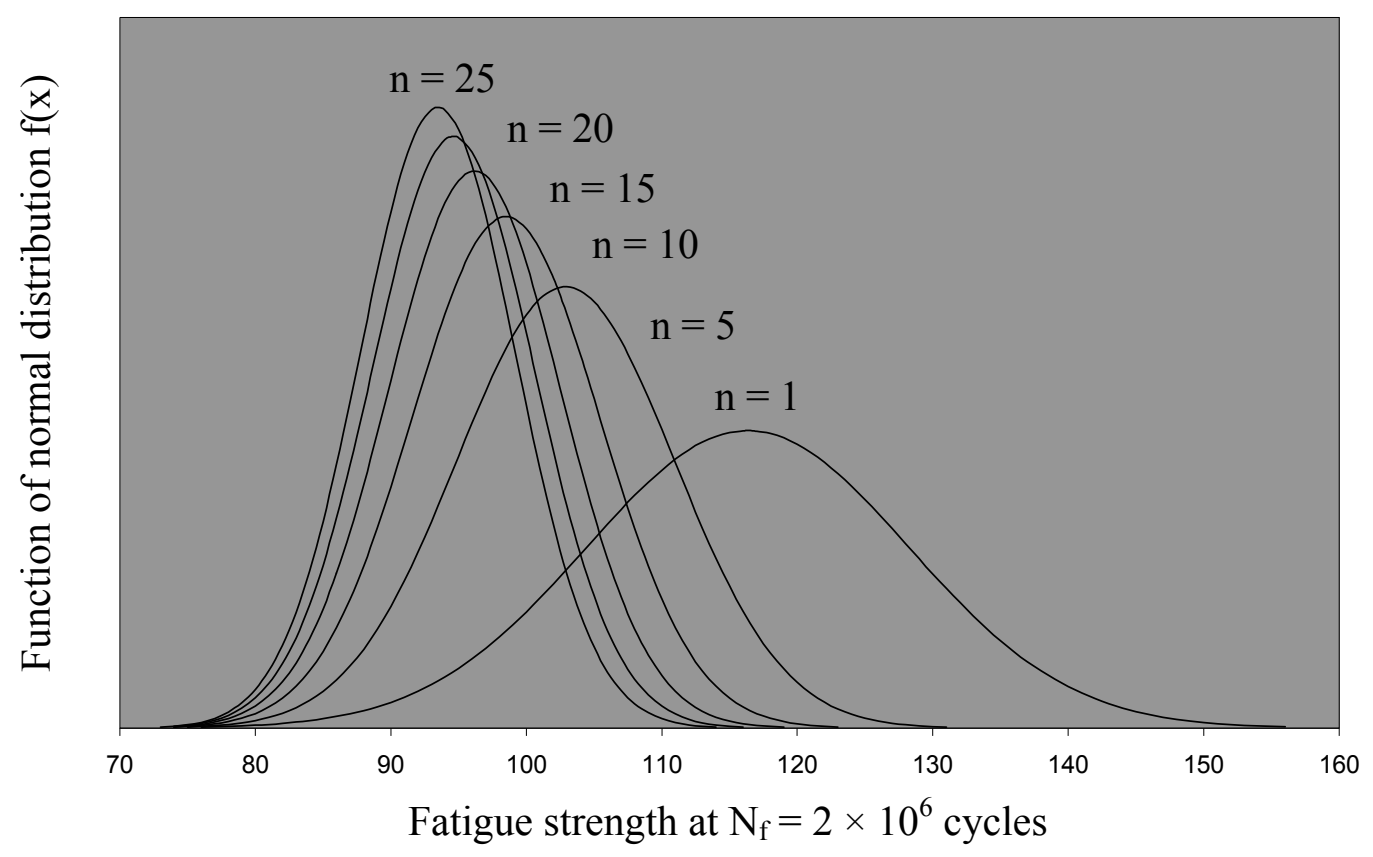

Figure 8. Normal Distribution for Number of Studs, $n$

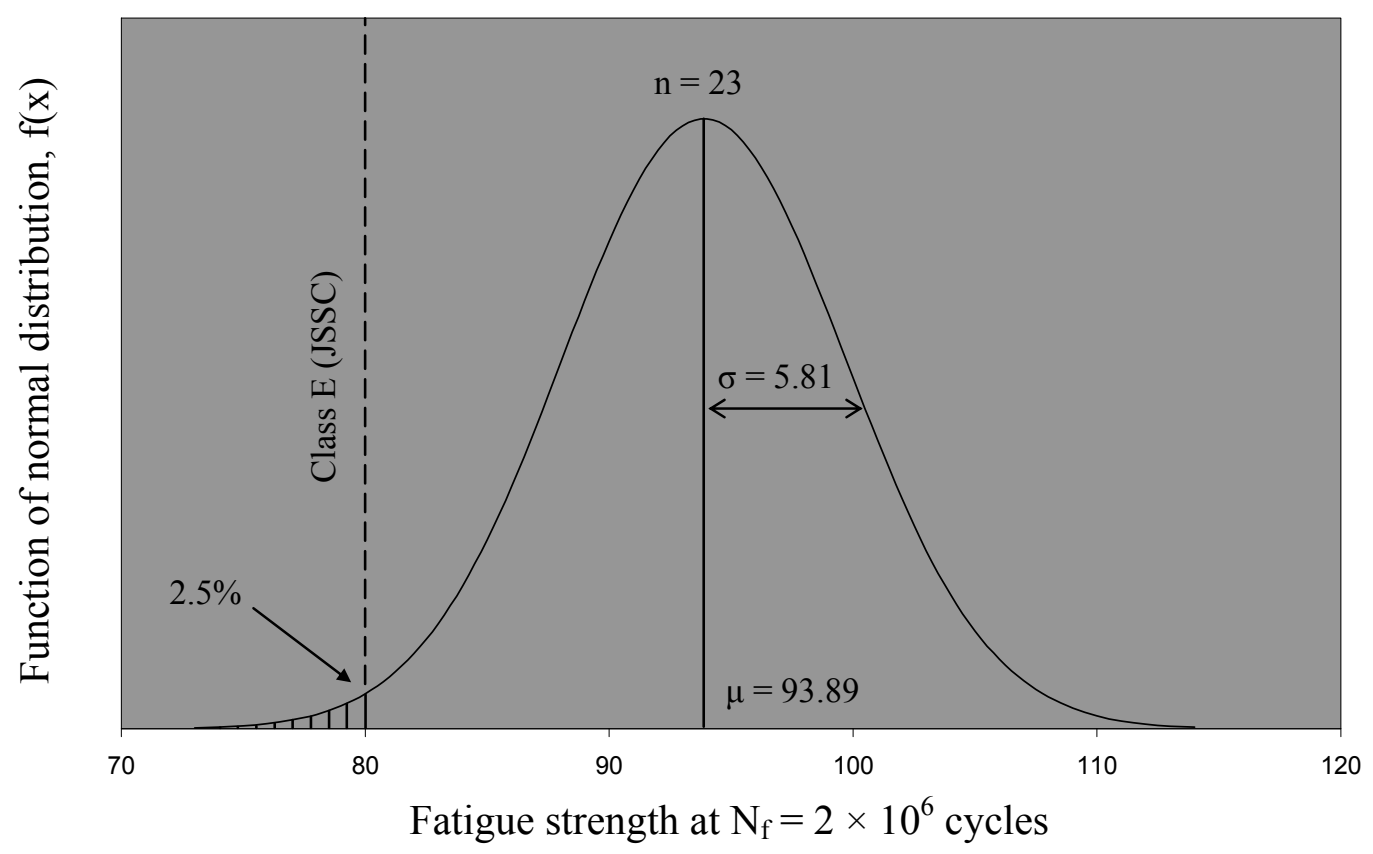

Figure 9. Normal Distribution for $\mathrm{n}=23$

The comparison of test results for steel plate welded with group of studs (type A and type B; consists of 3 specimens each) are not presented here because the S-N curve for both types are almost identical. This means that decreasing the spacing interval of $22 \mathrm{~mm}$ (refer Figure 4, 65-43 $=22 \mathrm{~mm}$ ) in the transverse direction to applied load has insignificant effect on fatigue strength of the studs. 


\section{DESIGN FORMULA USING d/t RATIO}

Test results data obtained for 'one stud' shown in Figure 6 are used to modify normal S-N equation by introducing ratio $d / t(d=$ stud diameter; $t=$ plate thickness $)$. Since the aim of this research is to deal with high cycle fatigue of offshore hybrid structures, the minimum cycles allowed are set to $1 \times 10^{5}$ cycles. For design purposes, using probability of failure of $2.5 \%$ of normal distribution as suggested by JSSC, the modified S-N equation for steel plate welded with stud is proposed under 2 conditions :

$S=\left[305\left(\frac{d}{t}\right)^{-\frac{3}{19}}-22\right]\left(\frac{N}{10^{5}}\right)^{-\frac{1}{3}}$

Conditions : 1) $\quad \mathrm{N} \geqslant 1 \times 10^{5}$ cycles

2) $d / t \leqslant 4.67$ (to be revised)

The value of $d / t=4.67$ in condition 2 is obtained by substituting $S_{r}=80 \mathrm{~N} / \mathrm{mm}^{2}$ (given by JSSC Class $\mathrm{E}$ curve) into modified equation at $\mathrm{N}_{\mathrm{f}}=2 \times 10^{6}$ cycles. However, it is to bear in mind that condition 2 is not practical and applicable because 4.67 is somehow an irrational value for $\mathrm{d} / \mathrm{t}$. Hence, future study on allowable limit of $\mathrm{d} / \mathrm{t}$ and/or revision of $\mathrm{S}_{\mathrm{r}}=80 \mathrm{~N} / \mathrm{mm}^{2}$ used in JSSC Class $\mathrm{E}$ are of important necessity for the proposed modified $\mathrm{S}-\mathrm{N}-\mathrm{d} / \mathrm{t}$ equation to be applied more effectively.

It is necessary to prove the reliability of statistical analysis used for derivation of modified equation. Referring to Figure 6, comparison is to be made for fatigue strength at $\mathrm{N}_{\mathrm{f}}=2 \times 10^{6}$ cycles between 'one stud' and 'group of studs' at $n=3$. Number of studs, $n$ is set as 3 because 3 studs failed along the cracking line for each specimen of steel plate welded with group studs. Fatigue strength for $n=$ 3 based on 'one stud' data is calculated using statistical equation in section 4 while fatigue strength of $n=3$ for 'group of studs' are obtained directly, based on experimental data from Figure 6 .

Using $\mu=116.35 \mathrm{~N} / \mathrm{mm}^{2}$ and $\sigma=11.91 \mathrm{~N} / \mathrm{mm}^{2}$ obtained from 'one stud' data, and $n=3$ :

$$
\begin{aligned}
\mathrm{P}[\mathrm{X}<116.35] & =1-\left[1-\phi\left(\frac{x-116.35}{11.91}\right)\right]^{n} \\
0.5 & =1-\left[1-\phi\left(\frac{x-116.35}{11.91}\right)\right]^{3} \\
{\left[1-\phi\left(\frac{\mathrm{S}-116.35}{11.91}\right)\right]^{3} } & =0.5 \\
\frac{\mathrm{S}-116.35}{11.91} & =-0.8193 \\
\mathrm{~S} & =106.6 \mathrm{~N} / \mathrm{mm}^{2}
\end{aligned}
$$

Next, with reference to Figure 6, the equation of S-N curve for 'group studs' is obtained as :

$$
\mathrm{S}=11098 N^{-0.3205}
$$


Since the comparison is made at number of cycles, $\mathrm{N}_{\mathrm{f}}=2 \times 10^{6}$ cycles :

$$
\begin{aligned}
\mathrm{S} & =11098\left(2 \times 10^{6}\right)^{-0.3205} \\
& =106.1 \mathrm{~N} / \mathrm{mm}^{2}
\end{aligned}
$$

Consequently, the fatigue strength for number of studs, $n=3$ for 'one stud' and 'group of studs' are obtained as $106.6 \mathrm{~N} / \mathrm{mm}^{2}$ and $106.1 \mathrm{~N} / \mathrm{mm}^{2}$ respectively with merely a difference of $0.5 \%$. This shows that statistical analysis method is reasonably reliable for derivation of modified equation.

Modified S-N-d/t equation is compared against actual test data in Figure 7. The results give positive satisfaction where actual test data for $\mathrm{d} / \mathrm{t}$ of $0.727,2.167,2.667$ and 3.167 surpassing the modified $\mathrm{S}-\mathrm{N}-\mathrm{d} / \mathrm{t}$ equation respectively (actual test data should always above $\mathrm{S}-\mathrm{N}$ curve in design) as shown in Figure 10.

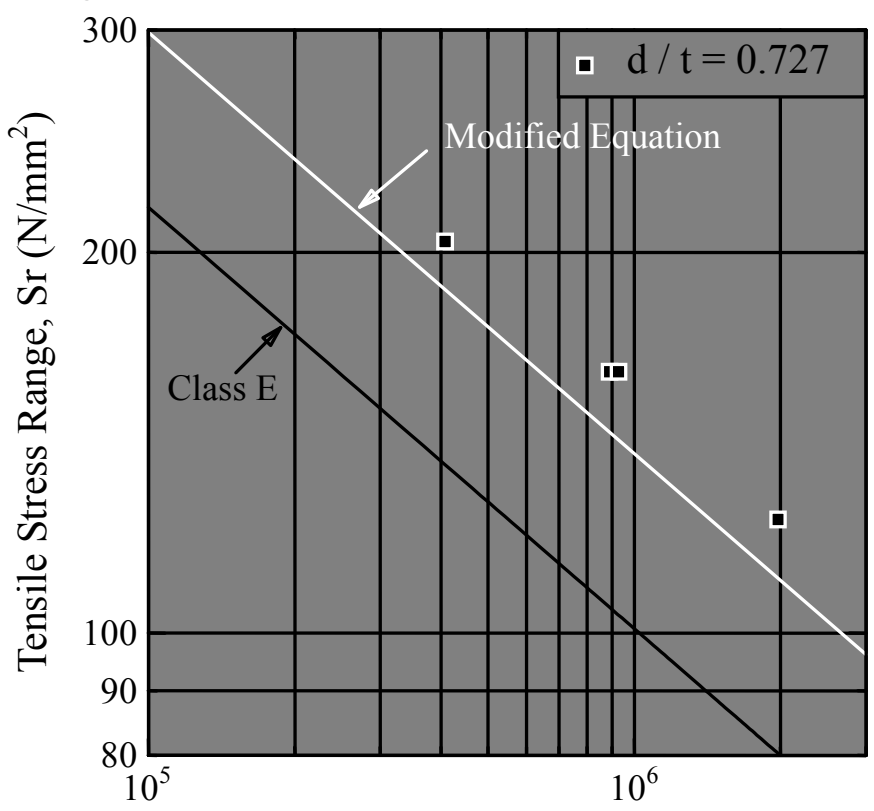

Number of Cycle to Failure, $\mathrm{N}_{\mathrm{f}}$

(a)

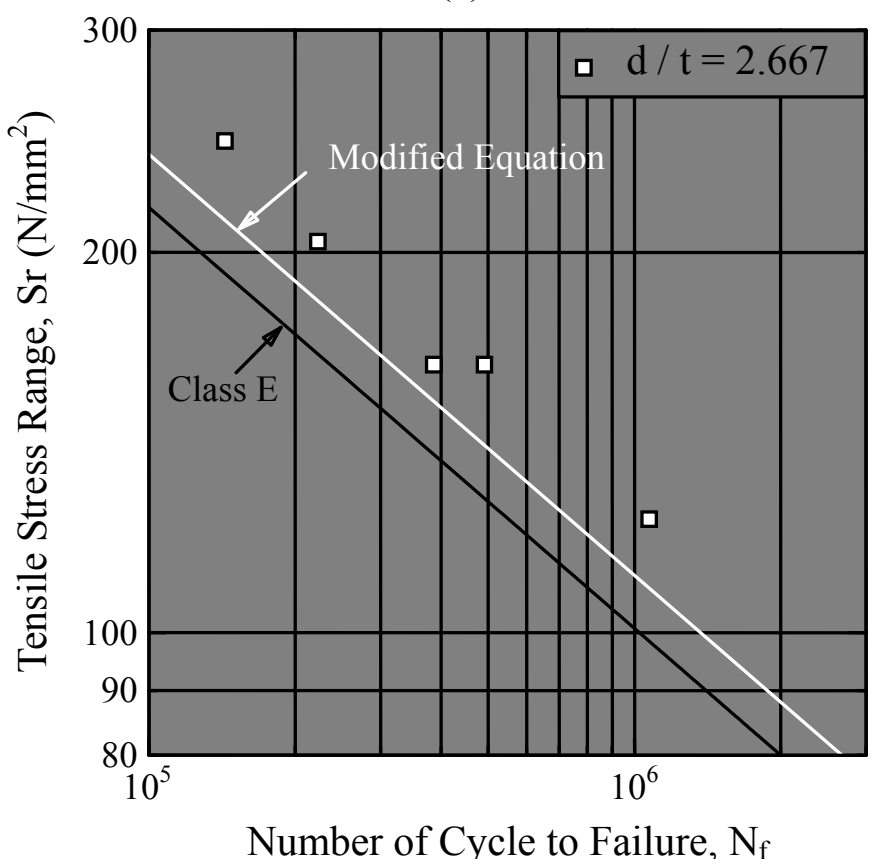

(c)

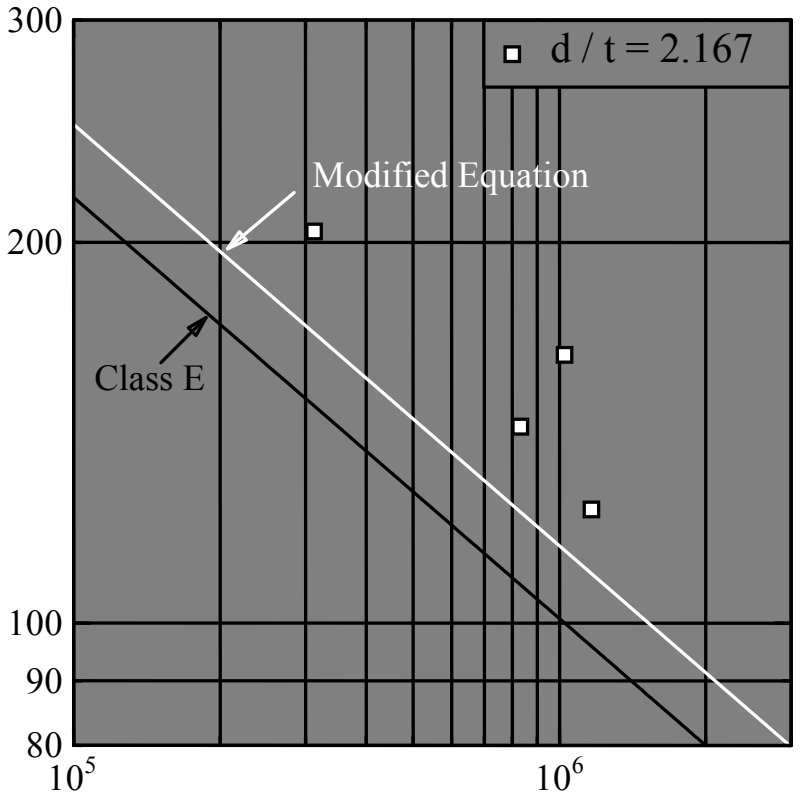

Number of Cycle to Failure, $\mathrm{N}_{\mathrm{f}}$

(b)

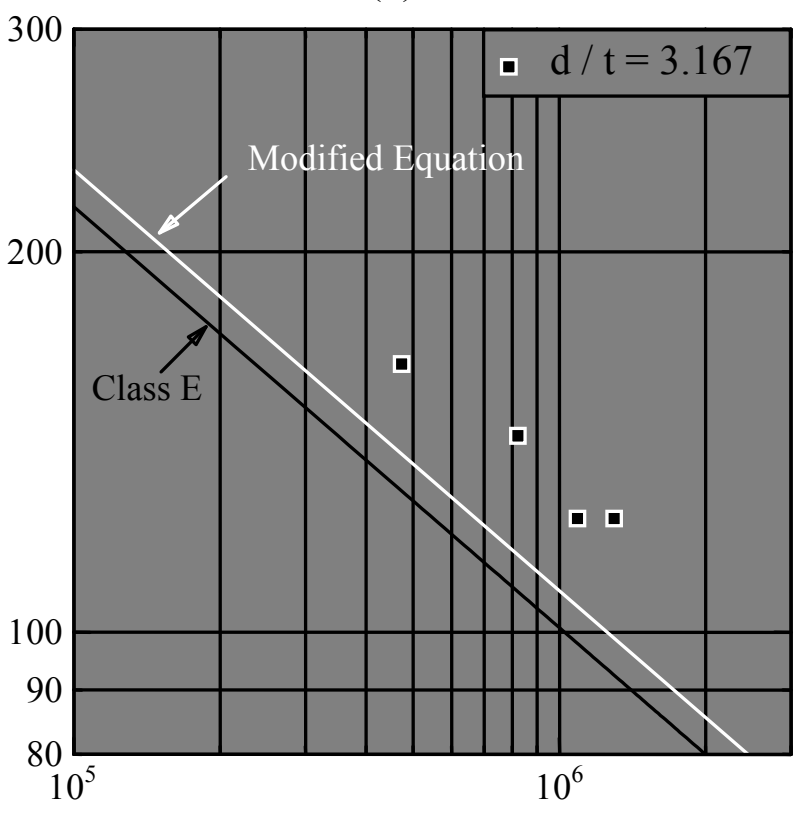

Number of Cycle to Failure, $\mathrm{N}_{\mathrm{f}}$

(d)

Figure 10. Actual Test Data Plotted Against Modified S-N-d/t Equation 


\section{FINITE ELEMENT METHOD (FEM) ANALYSIS}

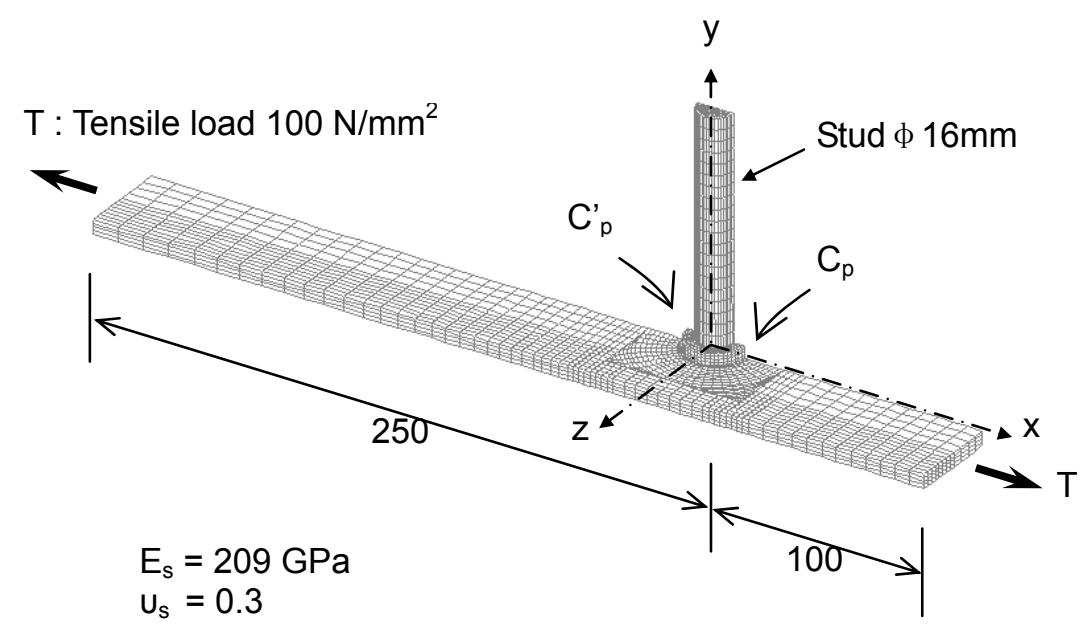

Figure 11. Finite Element Mesh Division (Half Model)

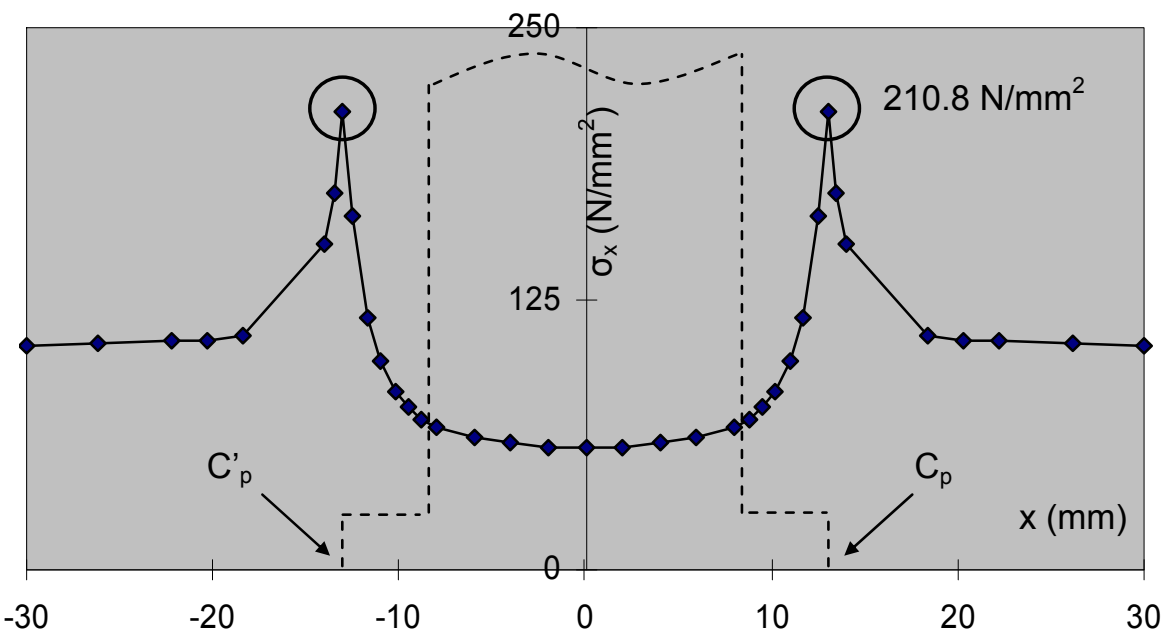

(a) x-direction

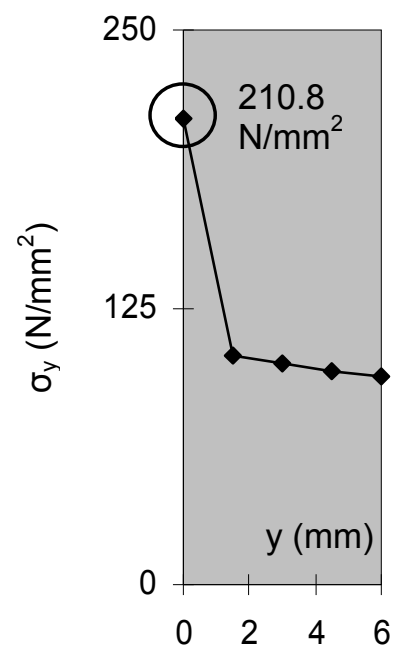

(b) y-direction

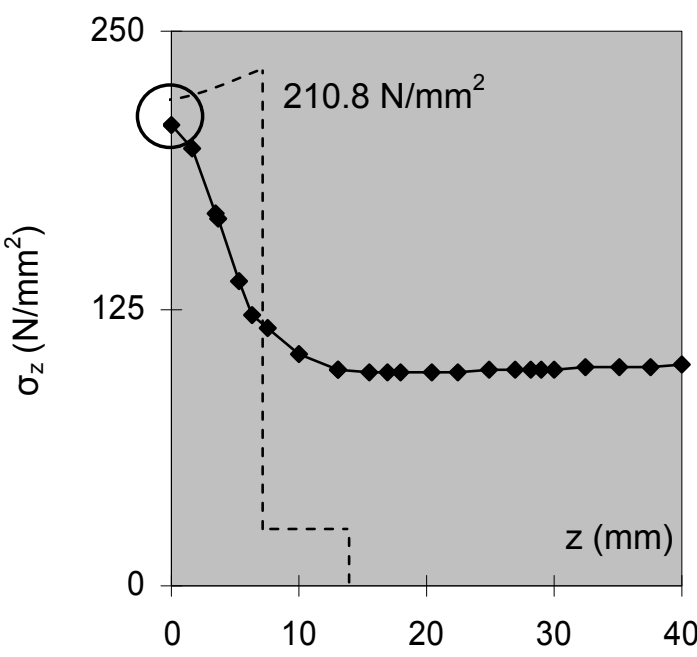

(c) z-direction

Figure 12. Stress Distribution under Tensile Load in $\mathrm{x}, \mathrm{y}$ and z-direction 
Software analyses are performed using LUSAS finite element analysis for steel plate welded with stud. Model is built in 3D $(350 \times 80 \times 6 \mathrm{~mm})$ with stud diameter of $16 \mathrm{~mm}$. Distributed tensile load of $100 \mathrm{~N} / \mathrm{mm}^{2}$ is applied to the specimen (Figure 11). The load is applied at an end distance of 250 $\mathrm{mm}$ and $100 \mathrm{~mm}$ from center of stud in order to simulate the half model condition of fatigue tests for steel plate welded with studs (Figure 3). Specimen is fixed in y-direction and critical points for maximum stresses at the edge of weld collar are represented by coordinate $C_{p}$ and $C_{p}$.

Stress distribution at weld collar of stud in $\mathrm{x}, \mathrm{y}$ and $\mathrm{z}$ direction are as shown in Figure 12. The value of maximum stress at $C_{p}$ (or $C_{p}^{\prime}$ ) is obtained as $210.8 \mathrm{~N} / \mathrm{mm}^{2}$ which gives a stress concentration factor approximately 2.1 , twice the applied tensile load of $100 \mathrm{~N} / \mathrm{mm}^{2}$. It is assumed that the factor that gives dominant impact to deterioration of fatigue strength is due to the discontinuity of geometrical form of weld collar especially at the bottom surface of the weld [6]. By referring to the modified S-N-d/t equation, an increase of stress concentration factor will results in the decrease of fatigue life, $\mathrm{N}$.

\section{CONCLUSIONS}

Few main conclusions that can be derived are listed as below :

i) Increasing the number of studs results in the decrease of fatigue strength (Figure 8). This is due to the fact that natural cracks will occur at the time when stud is welded to steel plate. Hence, number of cracks will increase with number of welded studs, resulting in decrease of fatigue strength. This statement is referred to Figure 6 ; it can be seen that S-N curve at $2 \times 10^{6}$ cycles for 'group studs' is lower than 'one stud'.

ii) Due to reason in i), maximum number of studs that can be welded in a row for an area of steel plate surface in the direction of force has to be obtained. By using statistical approach and conditions provided by Class E curve (JSSC), maximum number of studs are obtained as 23 . This means that as long as the numbers of welded studs are less than $23(n \leq 23)$, Class $\mathrm{E}$ is safe to be used as design limit curve.

iii) It is thought that $\mathrm{d} / \mathrm{t}$ ratio will has effect on the fatigue strength, and this is confirmed by the experimental data as shown in Figure 7. Using the combination of statistical approach and experiment data, normal S-N curve is modified by inserting $d / t$ element and the new S-N design limit curve is proposed under 2 conditions as below :

$S=\left[305\left(\frac{d}{t}\right)^{-\frac{3}{19}}-22\right]\left(\frac{N}{10^{5}}\right)^{-\frac{1}{3}}$

Conditions : $\quad 1) \mathrm{N} \geqslant 1 \times 10^{5}$ cycles (high cycle fatigue)

2) $d / t \leqslant 4.67$ (to be revised)

iv) Experiment is also conducted with the aim to test the validity of JSSC Class E design limit curve. The results show that all test data surpass JSSC Class E design limitation curve as shown in Figure 6.

v) FEM analysis is performed to observe the stress distribution in the vicinity of stud in $\mathrm{x}, \mathrm{y}$ and $\mathrm{z}$-direction. Analysis results show that the maximum stress is as high as twice the applied load, i.e. $210.8 \mathrm{~N} / \mathrm{mm}^{2} \div 100 \mathrm{~N} / \mathrm{mm}^{2}=$ stress concentration factor of 2.1 (Figure 12), in all direction 
occurring at the edge of weld collar. A higher stress concentration factor will results in the decrease of fatigue life, $\mathrm{N}$ as suggested by the modified $\mathrm{S}-\mathrm{N}-\mathrm{d} / \mathrm{t}$ equation.

vi) Further studies are needed on the limitations so as to enable the modified $\mathrm{S}-\mathrm{N}-\mathrm{d} / \mathrm{t}$ equation to be applied more effectively. Allowable limit of $\mathrm{d} / \mathrm{t}$ ratio and spacing interval between studs in the direction of applied load will be important topics for future research. Also, since the studs are mostly used in composite structures, the effect of concrete strength should be taken into consideration to remodify the proposed modified equation. Despite the fact that fatigue test is a time-consuming experiment, future experiments should be carried out with ample specimens in order to obtain higher accurate data for higher reliability of analysis.

\section{REFERENCES}

[1] Tanaka, M., Uebayashi, S., Wakana, H., and Watabiki, T., "Application of Caisson as Hybrid Structure in Harbor Construction (in Japanese)", $2^{\text {nd }}$ Symposium on Application of Composite Structure, Society of Civil Engineering, 1989, pp. 385-390.

[2] Maeda, Y., Matsui, S., and Hiragi, H., "Effects of Concrete-Placing Direction on Static and Fatigue Strengths of Stud Shear Connectors (in Japanese)", Technology Reports of The Osaka University, 1983, Vol. 33, No. 1733, pp. 397-406

[3] Nobuhito, O., Akimitsu, K., Keiichi, K., and Yasuhiro, I., "Experimental Study on Static and Fatigue Characteristics of Grouped Stud", Journal of Structural Engineering III, 2002, Vol. 48A, No. 13-14, pp. 1391-1398.

[4] "Fatigue Design Code for Steel Structures (in Japanese)", Japanese Society of Steel Construction (JSSC), 1993, pp. 6, 24.

[5] Eiichi, M., "Statistical Mathematics", Japan Science and Engineering Ltd., 1974, pp. 155-156.

[6] Kajikawa, Y., and Maeda, Y., "Fatigue Strength of Flange Plate with Stud Shear Connector Subjected to Combined Tension and Shear (in Japanese)", Journal of Civil Engineering, 1985, Vol. 362, No. I-4, pp. 285-292. 